\title{
Research on a method of hull form design based on wave-making resistance optimization
}

\author{
Jianglong Suna), Ph.D., Assoc. Prof. \\ Xujian Lva), Ph.D. \\ Weibin Liua), Ph.D., Assoc. Prof. \\ Hanwen Ning b), Ph.D. \\ Xianwen Chena), Master Graduate Student \\ a) Huazhong University of Science \& Technology, Wuhan, P.R. China \\ b) Zhongnan University of Economics and Law, Wuhan, P.R. China
}

\begin{abstract}
In this paper, we consider an optimization of the hull shape in order to minimize the total resistance of a ship. The total resistance is assumed to be the sum of the wave resistance computed on the basis of the thin-ship theory and the frictional resistance. Smoothness of hull lines is proved with mathematical procedure, in which differentials of the hull lines functions are analyzed. The wave-making resistance optimization, involving a genetic algorithm, uses Michell integral to calculate wave resistance. A certain hull form is generated by the method using cross section information of a modified DTMB model ship 5415 and a comparative experiment is carried out. Experimental and calculation result show that the method is of good adaptability for designing certain types of ships with excellent resistance performance.
\end{abstract}

Key words: hull lines design; wave-making resistance; optimization

\section{INTRODUCTION}

Resistance performance has a significant effect on the operating cost of civil ships and the survivability of military ship. In the optimization design of the hull, it is the total resistance that people care about most [4, 19], which is generally the sum of the viscous resistance and the wave-making resistance. In a sense, once the principal dimensions of a hull are determined, there is no significant wetted surface change and the optimization design of hull form is to obtain a hull form with the minimum wave-making resistance [1]. Further more, for highspeed ship, it is reasonable to take the wave-making resistance as a major objective in the optimization design because of its high proportion in the total resistance [22].

Wave-making resistance can be greatly reduced by employing excellent hull form or optimization of some existing hull offsets. Shape optimization is a growing field of interest in many areas of research, such as marine design and manufacturing. Wilson, Hendrix, and Gorski [20] develop a computational tool set and process framework help designers to decide the hull shape, which had great effect on its hydrodynamic characteristics.

In order to obtain a hull with the minimum wave-making resistance, designers often try to make improvement of parent hull. This requires lots of ship design experience, without mentioning the uncertain improvement [21]. Chen and Guang [2] optimized the shape of the after hull based on the desired wake distribution, using B-spline surface method to generate the surface geometry of ship. Peri, Rossetti, and Campana [16] carried out numerical shape optimization of a tanker ship with the aid of CFD techniques and experimentally verified. The hull form optimization often concerns one of the most important applications of wave-making resistance theories. Grigoropoulos and Chalkias [7] developed a formal methodology for the hull form optimization, using parametric hull form modeling to generate the variant hull forms, in which Rankine-source panel method and strip theories were both involved.

Development of a three-dimensional hull fairing form is one of the main requirements in the design of a marine vehicle. The final hull form must satisfy both the desired shape and performance characteristics, such as resistance performance [17]. Ghassemi and Ghiasi [6] developed a numerical program to determine the total resistance of planing crafts, and four different hull forms of Series 62 model 4666 planning craft were presented as calculation examples. A parametric approach to design of hull form was studied by Zhang, Zhu, and Leng [23], which provided the means for quick generation and variation of hull form for the hydrodynamic optimization of hull form. Pérez, Clemente, Suárez, and González [14] used explicit spline curves to make a wire model of the ship stations. An inverse design algorithm in determining the optimal shape of the bulbous bow was developed by Chen, Huang, and Fang [3], with the Levenberg-Marquardt method and B-spline surface control technique utilized.

Genetic algorithm has been used widely in hull design since it appeared several yeast ago. A Multidisciplinary design 
optimization method was used to optimize the DTMB model ship 5415 by Peri and Campana [15], while Gammon [5] conducted optimization to fishing vessels applying a MultiObjective Genetic Algorithm. Li [10] proposed a hybrid approach for multi-objective optimization of ship's principal parameters in conceptual design, employing a multiple objective genetic algorithm. Lu, Lin, and Ji [11] calculated the free trim hydrostatic ship characteristics applying the genetic algorithm, and some necessary improvement was made in practice to speed up the evolution. Kim and Yang [9] utilized A multi-objective genetic algorithm to develop a hull surface modification technique for the CFD-based hull form optimization.

Mathematical ship enjoys popularity among ship designers due to its good adaptability and excellent processing performance [12].The paper is going to develop a method for mathematical hull lines design, including the optimization calculation of the ship resistance. A kind of quadratic curve is used to generate a certain hull of the minimum wetted surface, and smoothness of the designed lines is discussed. A genetic algorithm is used to modify cross section of the hull and Michell integral is applied to solve the wave-making resistance in the optimization procedure. Numerical calculations and comparative experiments are conducted to assess the availability of the method.

\section{HULL LINES DESIGN}

\section{Cross section constructed by quadratic curve}

Quadratic curve is applied to construct cross section of the hull; the main process is discussed in the following parts. There are some conditions must be meet first:

Condition 1: The ship has only one symmetric plane called the centerplane. The shape of underbody of the ship is shown in Fig. 1.

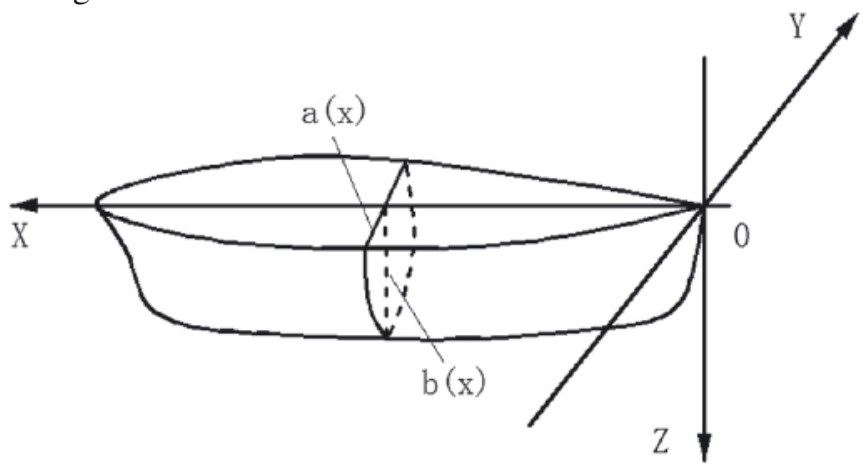

Fig. 1. Underbody of the hull

Condition 2: Half of the cross section presents with certain types of shape as Fig. 2 shows.
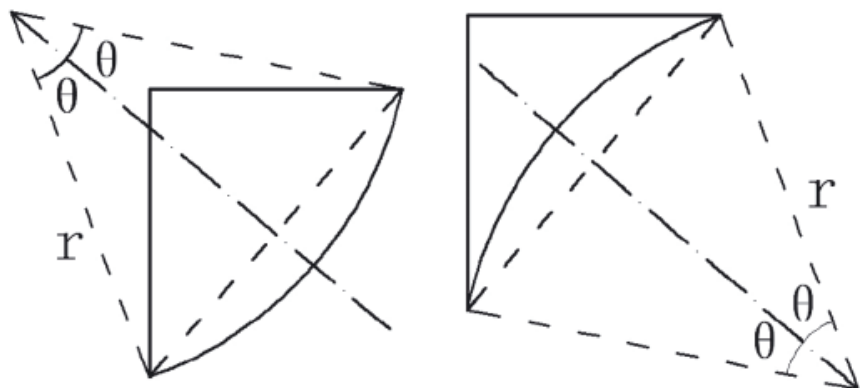

Fig. 2. Certain types of cross section constructed with arc curve

Condition 3: Both the middle buttock line and designed waterline are fairing.
A Cartesian coordinate system, as shown in Fig. 1, is defined with the $\mathrm{x}$-axis coincident with heading direction of the ship, and positive distance measured upstream. Let $\mathrm{L}$ be hull length, so the value of $X$ ranges in $[0, L]$. Middle line $L_{1}$ is indicated with function $\mathrm{b}(\mathrm{x})$, designed waterline $\mathrm{L}_{2}$ with function $\mathrm{a}(\mathrm{x})$, and half of cross section area with function $\mathrm{S}(\mathrm{x})$. Within the scope of $[0, L], a(x), b(x)$ and $S(x)$ are all bounded and smooth functions, and their first derivatives are continuous. As the hull has a symmetry plane called the middle sheer plane, only hull lines and section areas of the starboard side $(y \geq 0)$ are discussed. The paper is to discuss the underbody of hull, and lines above the designed waterline will not be involved.

The shape of the underbody, which can be expressed by a bunch of body lines, is indicated with a mathematical equation as follows:

$$
\frac{\mathrm{z}^{2}}{\mathrm{~b}(\mathrm{x})^{2}}+\frac{\mathrm{y}^{2}}{\mathrm{a}(\mathrm{x})^{2}}+\mathrm{czy}=1
$$

Where $\mathrm{c}=\mathrm{c}(\mathrm{x})$ is an undetermined parameter used to modify the cross section. A new parameter $\beta$ is introduced:

$$
\beta(x)=2 S(x) / a(x) b(x)
$$

Assuming that cross section area of the hull reaches the maximum when $\mathrm{x}=\mathrm{L} / 2$, that is to say, there exists $\mathrm{x}_{0} \in[0, \mathrm{~L} / 2]$ making $\beta\left(\mathrm{x}_{0}\right)=1$.

\section{Mathematical analysis of the approximate minimum wetted surface area}

To gain a hull of good resistance performance, mathematical process is taken to analysis character the quadratic curve that constructs the cross section. As we know, arc length is the shortest to that of any curve with the same area. A comparison of the length between the curves mentioned above is taken in this section.

As it is shown in Fig. 2, the circular arc is defined with radius $r$ and central angle $2 \theta$. We have:

$$
\left\{\begin{array}{l}
r \sin \theta=\frac{1}{2} \sqrt{a(x)^{2}+b(x)^{2}} \\
r^{2} \theta=\frac{1}{2} \sqrt{a(x)^{2}+b(x)^{2}} r \cos \theta+S(x)-\frac{1}{2} a(x) b(x)
\end{array}\right.
$$

Let $1_{\text {circle }}$ be length of the circular arc, then:

$$
1_{\text {circle }}=2 \mathrm{r} \theta
$$

The quadratic curve can be expressed as:

$$
y(z)=-\frac{1}{2} a(x)^{2} c z+a(x) \sqrt{1-\left(\frac{1}{b(x)^{2}}-\frac{1}{4} a(x)^{2} c^{2}\right) z^{2}}
$$

Let $l_{\text {conic }}$ be length of the quadratic curve, then:

$$
1_{\text {conic }}=\int_{0}^{\mathrm{b}(\mathrm{x})} \sqrt{1+\left[\mathrm{y}^{\prime}(\mathrm{z})\right]^{2}} \mathrm{dz}
$$

Area of cross sections:

$\mathrm{S}(\mathrm{x})=\int^{\mathrm{b}(\mathrm{x})}\left(-\frac{1}{2} \mathrm{a}(\mathrm{x})^{2} \mathrm{cz}+\mathrm{a}(\mathrm{x}) \sqrt{1-\left(\frac{1}{\mathrm{~b}(\mathrm{x})^{2}}-\frac{1}{4} \mathrm{a}(\mathrm{x})^{2} \mathrm{c}^{2}\right) \mathrm{z}^{2}}\right) d \mathrm{z}$

The discussion of Eq. (1) for $\mathrm{x}<\mathrm{x}_{0}, \mathrm{x}=\mathrm{x}_{0}$ and $\mathrm{x}>\mathrm{x}_{0}$ is detailed in appendix A and Length of the two kinds of curve mentioned above are calculated. Solutions of the Eq. (1) are discussed as well and the conclusion becomes: 
- $\quad$ when $0 \leq \mathrm{x}<\mathrm{x}_{0}$, namely $\beta(\mathrm{x})=2 \mathrm{~S}(\mathrm{x}) / \mathrm{a}(\mathrm{x}) \mathrm{b}(\mathrm{x})<1$, and $c>2 / a(x) b(x)$ Eq. (1) has at least one nontrivial solution; when $\mathrm{x}=\mathrm{x}_{0}$, namely: $\beta(\mathrm{x})=2 \mathrm{~S}(\mathrm{x}) / \mathrm{a}(\mathrm{x}) \mathrm{b}(\mathrm{x})=1$, and $\mathrm{c}=2 / \mathrm{a}(\mathrm{x}) \mathrm{b}(\mathrm{x}) \mathrm{Eq}$. (1) has at least one nontrivial solution; - when $\mathrm{x}<\mathrm{x}_{0} \leq \mathrm{L} / 2$, namely: $\beta(\mathrm{x})=2 \mathrm{~S}(\mathrm{x}) / \mathrm{a}(\mathrm{x}) \mathrm{b}(\mathrm{x})>1$, and $\mathrm{c}<2 / \mathrm{a}(\mathrm{x}) \mathrm{b}(\mathrm{x})$ Eq. (1) has at least one nontrivial solution.

With a set of cross sections, of which breadths, draughts and areas are limited in a certain range, one can calculate the length of the designed quadratic curve and the circular arc. Most of the relatively error is less than $0.05 \%$ by comparing the designed quadratic curves with circular arcs, as illustrated in Fig. 3, and the maximum error is only $0.11 \%$.

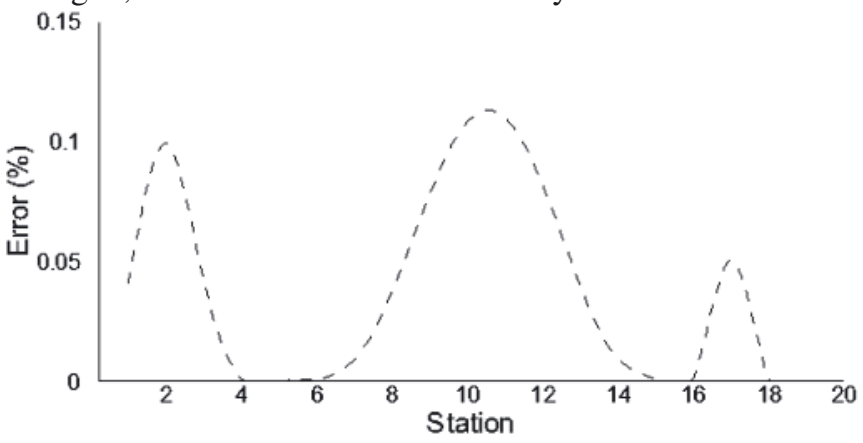

Fig. 3. Length error of the designed curve to circular arc at every station

It is not difficult to get a conclusion that hulls consisted of the designed cross section curves can be approximately seen as hulls of the minimum wetted area.

\section{Simple mathematical discussion of rationality of the designed hull lines}

In the following part, whether the designed lines are accordant with the practical situation is discussed, that is:

- whether the first derivatives with respect to $\mathrm{x}$ of any waterline and buttock line are smooth.

whether changes of signs of the second derivative with respect to $\mathrm{x}$ of any waterline and buttock line are in accordance with general law of hull lines.

A theorem for implicit differentiation is introduced firstly. Suppose that $\mathrm{F}(\mathrm{y}, \mathrm{z})$ meets the following conditions:

- in the domains $\left|\mathrm{z}-\mathrm{z}_{0}\right| \leq \delta$ and $\left|\mathrm{y}-\mathrm{y}_{0}\right| \leq \lambda$, both $\mathrm{F}_{\mathrm{z}}$ and $\mathrm{F}_{\mathrm{y}}$ are continuous.

- $\mathrm{F}\left(\mathrm{y}_{0}, \mathrm{z}_{0}\right)=0$

- $\mathrm{F}_{\mathrm{y}}\left(\mathrm{y}_{0}, \mathrm{z}_{0}\right) \neq 0$

These lead to some conclusions:

- in a certain neighborhood of point $\left(\mathrm{y}_{0}, \mathrm{z}_{0}\right), \mathrm{F}(\mathrm{y}, \mathrm{z})=0$ uniquely determines a function $\mathrm{y}=\mathrm{f}(\mathrm{z})$; and $\mathrm{y}_{0}=\mathrm{f}\left(\mathrm{z}_{0}\right)$. In other words, $\mathrm{y}=\mathrm{f}(\mathrm{z})$ is defined within a certain neighborhood $\mathrm{O}\left(\mathrm{z}_{0}, \eta\right)$ of $\mathrm{z}_{0}$, meeting $\mathrm{F}(\mathrm{z}, \mathrm{f}(\mathrm{z})) \equiv 0$ and $\mathrm{y}_{0}=\mathrm{f}\left(\mathrm{z}_{0}\right)$;

- $y=f(z)$ is continuous in the domain $\mathrm{O}\left(\mathrm{z}_{0}, \eta\right)$;

The first derivative of $y=f(z)$ is continuous in the domain $\mathrm{O}\left(\mathrm{z}_{0}, \eta\right)$, and at any point where $\mathrm{F}_{\mathrm{y}} \neq 0, \mathrm{y}^{\prime}=-\mathrm{F}_{\mathrm{z}}(\mathrm{y}, \mathrm{z}) / \mathrm{F}_{\mathrm{y}}(\mathrm{y}, \mathrm{z})$.

On the basis of the theorem mentioned above, the implicit function that $\mathrm{c}=\mathrm{c}(\mathrm{x})$ meets is analyzed as follows:

- when $0 \leq \mathrm{x}<\mathrm{x}_{0}$, namely $\beta(\mathrm{x})<1$, Eq. (A5) can be expressed as:

$$
\begin{aligned}
& F(x, c)=\exp \left(\beta \sqrt{\frac{a(x)^{2} b(x)^{2} c^{2}}{4}-1}\right)+ \\
& -\sqrt{\frac{a(x)^{2} b(x)^{2} c^{2}}{4}-1}-\frac{1}{2} a(x) b(x) c=0
\end{aligned}
$$

when $\mathrm{x}<\mathrm{x}_{0} \leq \mathrm{L} / 2$, namely $\beta(\mathrm{x})>1$, Eq. (A13) can be expressed as:

$$
\begin{aligned}
\mathrm{F}(\mathrm{x}, \mathrm{c}) & =\sin \left(\beta \cdot \sqrt{1-\frac{\mathrm{a}(\mathrm{x})^{2} \mathrm{~b}(\mathrm{x})^{2} \mathrm{c}^{2}}{4}}\right)+ \\
& -\sqrt{1-\frac{\mathrm{a}(\mathrm{x})^{2} \mathrm{~b}(\mathrm{x})^{2} \mathrm{c}^{2}}{4}}=0
\end{aligned}
$$

For arbitrary $\mathrm{x} \in\left[0, \mathrm{x}_{0}\right)$ or $\mathrm{x} \in\left(\mathrm{x}_{0}, \mathrm{~L} / 2\right)$, it is easy to validate that $\mathrm{F}(\mathrm{x}, 2 / \mathrm{a}(\mathrm{x}) \mathrm{b}(\mathrm{x}))=0, \mathrm{~F}_{\mathrm{c}}(\mathrm{x}, 2 / \mathrm{a}(\mathrm{x}) \mathrm{b}(\mathrm{x})) \neq 0$, where $\mathrm{F}_{\mathrm{c}}$ and $\mathrm{F}_{\mathrm{x}}$ are continuous in a small enough neighborhood of $\mathrm{x}$.

In that case, it can be concluded that $\mathrm{c}=\mathrm{c}(\mathrm{x})$ is continuously differentiable function in domain $\left[0, \mathrm{x}_{0}\right)$ and $\left(\mathrm{x}_{0}, \mathrm{~L} / 2\right]$. Since both equations have the solution $\mathrm{c}\left(\mathrm{x}_{0}\right)=2 / \mathrm{a}\left(\mathrm{x}_{0}\right) \mathrm{b}\left(\mathrm{x}_{0}\right), \mathrm{c}=\mathrm{c}(\mathrm{x})$ is continuous in the domain [0, L/2]. A complete process is detailed in appendix B.

The first and second derivative of y can be written as:

$$
\begin{aligned}
& y^{\prime}(x)=-a^{\prime} a h-\frac{1}{2} a^{2} c^{\prime} h+a^{\prime} \sqrt{1-\left(\frac{1}{b^{2}}-\frac{1}{4} a^{2} c^{2}\right) h^{2}} \\
& +\frac{a h^{2}\left(\frac{b^{\prime}}{b^{3}}+\frac{1}{4} a a^{\prime} c^{2}+\frac{1}{4} a^{2} c c^{\prime}\right)}{\sqrt{1-\left(\frac{1}{b^{2}}-\frac{1}{4} a^{2} c^{2}\right) h^{2}}}, x \in[0, L / 2] \\
& y^{\prime \prime}(x)=-a^{\prime 2} c z-2 a^{\prime} c^{\prime} z-a c a " z+ \\
& -\frac{1}{2} a^{2} c^{\prime \prime} z+a " \sqrt{1-\left(\frac{1}{b^{2}}-\frac{1}{4} a^{2} c^{2}\right) z^{2}}+ \\
& \frac{a^{\prime}\left(-\frac{2 b^{\prime}}{b^{3}}-\frac{1}{2} a c^{2} a^{\prime}-\frac{1}{2} a^{2} c c^{\prime}\right) z^{2}}{\sqrt{1-\left(\frac{1}{b^{2}}-\frac{1}{4} a^{2} c^{2}\right) z^{2}}}+ \\
& -\frac{1}{4} \frac{a\left(-\frac{2 b^{\prime}}{b^{3}}-\frac{1}{2} a c^{2} a^{\prime}-\frac{1}{2} a^{2} c c^{\prime}\right)^{2} z^{4}}{\left(1-\left(\frac{1}{b^{2}}-\frac{1}{4} a^{2} c^{2}\right) z^{2}\right)^{3 / 2}}+ \\
& -\frac{1}{2} \frac{1}{\sqrt{1-\left(\frac{1}{b^{2}}-\frac{1}{4} a^{2} c^{2}\right) z^{2}}}\left[a \left(\frac{6 b^{\prime 2}}{b^{4}}-\frac{2 b^{\prime \prime}}{b^{3}}-\frac{1}{2} a^{\prime 2} c-2 a c a^{\prime} c^{\prime}+\right.\right. \\
& \left.\left.-\frac{1}{2} a c^{2} a "-\frac{1}{2} a^{2} c^{\prime 2}-\frac{1}{2} a^{2} c c^{\prime \prime}\right) z^{2}\right], x \in[0, L / 2]
\end{aligned}
$$

It is clear that the waterlines of the hull are feasible from the discussion above. Since $\mathrm{y}$ and $\mathrm{z}$ are interchangeable in Eq. (1), a similar conclusion about the buttock lines can be got as well.

\section{Wave-making resistance optimization and sample designs}

\section{Wave-making resistance calculation}

Since [13] published one of his scientific papers in 1898, the famous Michell integral has made great achievements in ship wave-making resistance and hull optimization. The basic formulas of Michell integral are written as follows [18]: 


$$
\begin{gathered}
\mathrm{R}_{\mathrm{w}}=\frac{4 \rho \mathrm{g}^{2}}{\pi \mathrm{U}^{2}} \int_{1}^{\infty}\left(\mathrm{I}^{2}+\mathrm{J}^{2}\right) \frac{\lambda^{2}}{\sqrt{\lambda^{2}-1}} \mathrm{~d} \lambda \\
\mathrm{I}=\iint_{\mathrm{H}} \eta_{\mathrm{x}}(\mathrm{x}, \mathrm{z}) \mathrm{e}^{\lambda^{2} \mathrm{gz} / \mathrm{U}^{2}} \cos \left(\lambda \mathrm{gx} / \mathrm{U}^{2}\right) \mathrm{dxdz} \\
\mathrm{J}=\iint_{\mathrm{H}} \eta_{\mathrm{x}}(\mathrm{x}, \mathrm{z}) \mathrm{e}^{\lambda^{2} \mathrm{gz} / \mathrm{U}^{2}} \sin \left(\lambda \mathrm{gx} / \mathrm{U}^{2}\right) \mathrm{dxdz}
\end{gathered}
$$

Where $\eta(x, z)$ defines the geometry of the hull, $g$ is acceleration of gravity and $\mathrm{U}$ indicates the moving velocity of hull. As have been defined above, $\mathrm{x}$-axis is coincident with heading direction of the ship, and z-axis is coincident with draught direction the ship.

In the research, a numerical program is conducted applying Michell integral to calculate wave-making resistance of hulls. Before the calculation, the Wigley N43 hull is used to check the accuracy of the numerical procedure. Line function of the hull can be written as [8]:

$$
\begin{aligned}
& y=\frac{B}{2} \times {\left[\left(1-\left(\frac{2 x}{L}\right)^{2}\right)\left(1-\left(\frac{z}{T}\right)^{2}\right)\left(1+0.2\left(\frac{2 x}{L}\right)^{2}\right)+\right.} \\
&\left.+\left(\frac{z}{T}\right)^{2}\left(1-\left(\frac{z}{T}\right)^{8}\right)\left(1-\left(\frac{2 x}{L}\right)^{2}\right)^{4}\right]
\end{aligned}
$$

Wave-making resistance coefficient $\mathrm{C}_{\mathrm{w}}$ is defined as:

$$
C_{w}=\frac{R_{w}}{\frac{1}{2} \rho D^{2 / 3} V^{2}}
$$

where $R_{w}$ is wave-making resistance of the hull in N, D is the hull displacement in $\mathrm{kg}$, and $\mathrm{V}$ is the heading velocity of the ship in $\mathrm{m} / \mathrm{s}$. Curves of $\mathrm{C}_{\mathrm{w}}$ versus Froude Number are presented in Fig. 4 to compare the result calculated in the program with that Wigley got from the calculations and experiments, with the ordinate representing the coefficient of wave-making resistance, and the abscissa the Froude number.

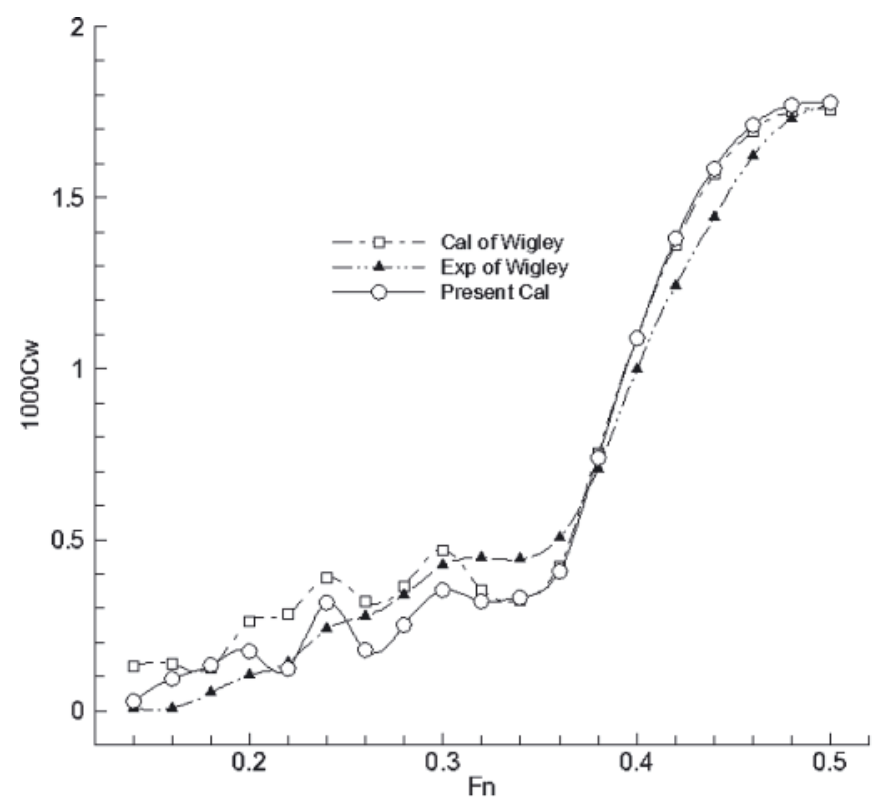

Fig. 4. Wave-making resistance comparison of present calculation with that of Wigley's and the experimental result for Wigley N43 model

As it is illustrated in Fig. 4, though the agreement of the calculation at low Froude Number is not so perfect, the result show in this paper shows good agreement with that Wigley got at high Froude Number ( Fr $>0.32)$.

\section{Genetic algorithm}

A genetic algorithm optimization model is applied and the numerical procedure is shown as follows:

The hull is divided into 21 stations in the direction of length. Since the section area of the No.0 station and No.20 station are zero, section areas of No.1 station to No.19 station are defined as designed variables:

$$
\bar{X}=\{x i\}, i-1,2, \ldots, 19
$$

Michell integration is used as the target function, that is, the adaptive function of genetic algorithm, and the volume of displacement of the ship as the constraint condition. 5 percentages more of section area of parent hull is taken as the upper limit of the optimum region $\left(\mathrm{X}_{\mathrm{U}}\right)$ while 5 percentages less of that as the lower limit of the optimum region $\left(\mathrm{X}_{\mathrm{L}}\right)$.Then, the optimum model can be expressed as:

$$
\begin{array}{ll}
\text { Target funktion Min } & \mathrm{R}_{\mathrm{w}}=\mathrm{R}_{\mathrm{w}}(\mathrm{X}, \mathrm{U}) \\
\text { Subject to } & \mathrm{g}_{1}: \mathrm{x}_{\mathrm{i}}>\mathrm{X}_{\mathrm{L}} \\
& \mathrm{g}_{1}: \mathrm{x}_{\mathrm{i}}<\mathrm{X}_{\mathrm{U}} \\
& \mathrm{g}_{1}:\left(\Delta-\Delta_{0}\right) / \Delta<5 \% \text { o }
\end{array}
$$

Where Rw is wave-making resistance, $\mathrm{U}$ is the moving velocity of hull and $\Delta$ indicates the volume displacement of the hull. Since the volume of displacement constraint condition is nonlinear, we use the punishment coefficient method to simplify the computational process, and the punishment function can be written as

$$
\mathrm{Rw}(\mathrm{X}, \mathrm{U}, \Delta)=\mathrm{Rw}+\mathrm{M}\left(\frac{\Delta-\Delta_{0}}{\Delta}\right)^{\mathrm{N}}
$$

Where $\mathrm{M}$ and $\mathrm{N}$ are coefficient that need to be determined. Since it is difficult for genetic algorithm to deal with both $\mathrm{M}$ and $\mathrm{N}$, we can make $\mathrm{N}$ constant and $\mathrm{M}$ a kind of descending series.

\section{Design sample and analysis}

Lines designing example of a hull is shown in the following, with the modified DTMB model ship 5415 used as the parent hull, of which the bulbous bow is removed. The main principles are listed in Table 1.

Tab. 1. Main parameters of the parent ship

\begin{tabular}{|c|c|}
\hline Parameter & Value \\
\hline Displacement [t] & 12129 \\
\hline Length overall [m] & 172.5 \\
\hline Beam [m] & 23.09 \\
\hline Depth [m] & 12.34 \\
\hline Volume of displacement $\left[\mathrm{m}^{3}\right]$ & 11785.6 \\
\hline Amid ship section coefficient $\mathrm{C}_{\mathrm{m}}$ & 0.817 \\
\hline Length on the waterline $[\mathrm{m}]$ & 160.0 \\
\hline Waterline breadth $[\mathrm{m}]$ & 21.46 \\
\hline Draught $[\mathrm{m}]$ & 6.927 \\
\hline Prismatic coefficient $\mathrm{C}_{\mathrm{p}}$ & 0.607 \\
\hline Block coefficient $\mathrm{C}_{\mathrm{h}}$ & 0.496 \\
\hline
\end{tabular}


Since the hull lines of new ship generated is similar to the parent hull as it is shown in Fig. 5, resistance test of 1/30 scale models of the two ships are performed in the towing tank of Huazhong University of Science \& Technology respectively for further comparison and analysis. The experimental temperature is about $18.0^{\circ} \mathrm{C}$, and the models are kept afloat on an even keel during the test. Some useful parameters are shown in Table 2.

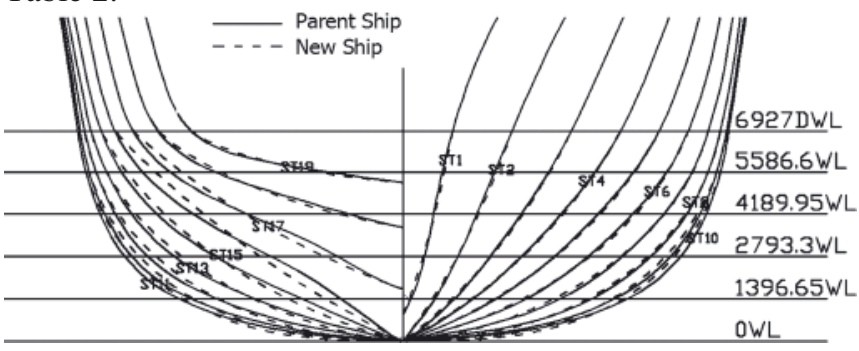

Fig. 5. Lines of the parent ship and the designed one

Tab. 2. Some useful information for the experiment

\begin{tabular}{|c|c|c|}
\hline Parameter & $\begin{array}{c}\text { Parent ship } \\
\text { model }\end{array}$ & $\begin{array}{c}\text { New ship } \\
\text { model }\end{array}$ \\
\hline Wetted surface area $\left[\mathrm{m}^{2}\right]$ & 3.893 & 3.905 \\
\hline Displacement $[\mathrm{kg}]$ & 438.5 & 436.0 \\
\hline Average draught $[\mathrm{m}]$ & 0.2309 & 0.2309 \\
\hline
\end{tabular}

The resistance of the models tested in the experiment is converted to that of the full-scale ships, and the total resistance coefficient and residual resistance coefficient of the hulls are shown in Fig. 6. Experimental result indicates that the resistance of the new ship is similar to that of the parent hull. With the velocity of full-scale ship ranging from 22 to 36 knots, the total resistance of designed hull is $1 \%$ averagely more than that of the parent ship. Taking the average accuracy of model experiment into account, a conclusion can be drawn that resistance of the designed ship has no obvious change compared with that of the parent hull (Fig. 6). Obviously, the wetted surface area of the new ship declines slightly. These is probably because: firstly, the wetted surface area coefficient of the parent ship model is too small to bear too much change; secondly, on the condition that the displacement and the principal dimensions are almost the same, when the character of the body lines changed a little, it leads to no big difference in decreasing the wetted surface area.



Fig. 6. Comparison of resistance coefficient of the new hull with that of the parent one
Optimization of designed ship of full-scale is conducted, using Michell integral and the genetic algorithm mentioned above. Some different velocities such as $26 \mathrm{kn}(\mathrm{Fr}=0.338)$, $28 \mathrm{kn}(\mathrm{Fr}=0.364), 30 \mathrm{kn}(\mathrm{Fr}=0.390), 32 \mathrm{kn}(\mathrm{Fr}=0.416)$ are taken into account. As have been stated, the wave-making resistance is taken as the target function. New section area curves of different resistance performance are obtained. The cross section area curves of different velocities are shown in Fig. 7, compared with that of parent ship.

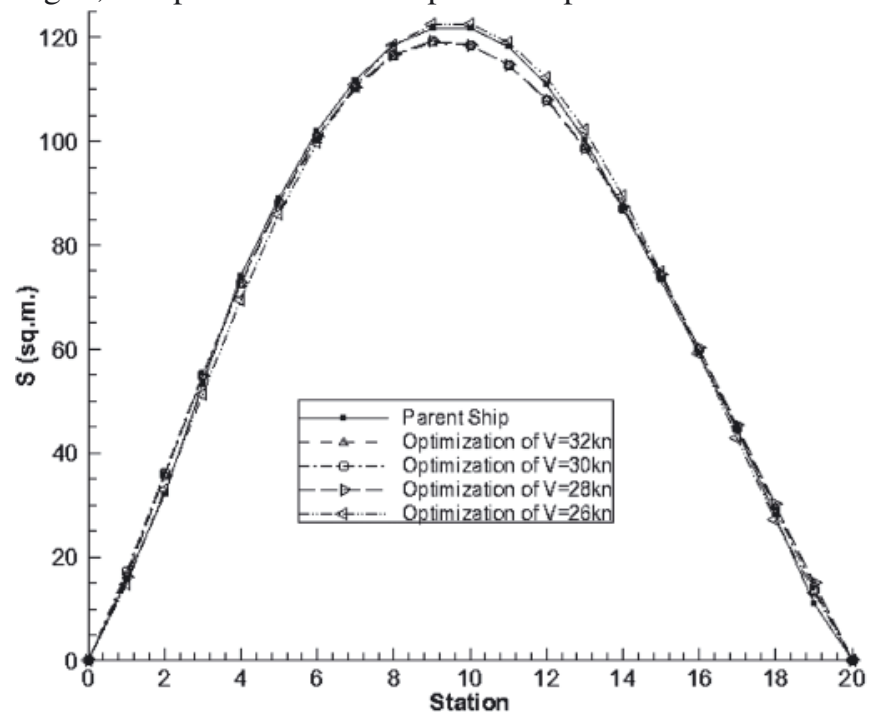

Fig. 7. Transverse-section area curves of different velocities optimization compared with that of parent ship

Comparison wave-making resistance coefficient is shown in Fig. 8. The calculation result of $26 \mathrm{kn}$ shows good resistance performance at low velocity, while the wave-making resistance at high speed has no obvious improvement. Calculation result of $28 \mathrm{kn}$ and $30 \mathrm{kn}$ show just a little change at low speed in wave-making resistance, but the improvement at high speed is noticeable. Based on an overall consideration of different velocities, optimization result of $28 \mathrm{kn}$ is chosen for hull lines optimization.



Fig. 8. Coefficient of wave-making resistance of different velocities optimization compared with that of parent ship

Wave-making resistance coefficients of parent hull and the optimized one at 28 knots, compared with experimental result, are shown in Fig. 9. Lines of the designed hull and the optimized one are shown in Fig. 10. Since cross section areas of the hull vary in a small range, lines of hull dose not have 
much change. That is to say, with just a little change of hull lines, the hull can get some noticeable improvement in wave making resistance performance.

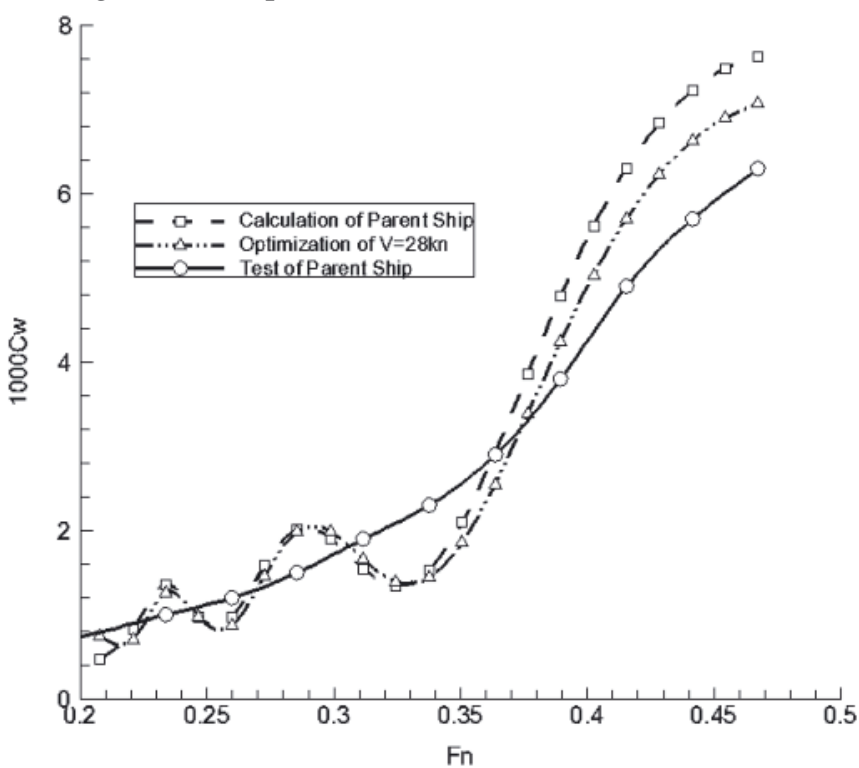

Fig. 9. Comparison of calculation result with experimental result

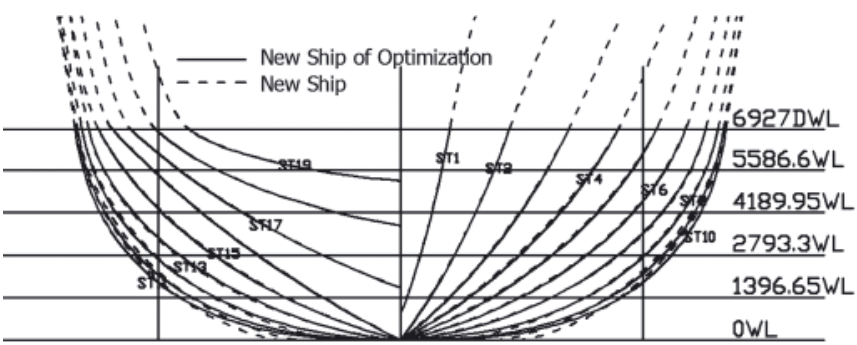

Fig. 10. Lines of the designed hull and the optimized one
In general, the wave-making resistance performance of the new hull is close to that of the parent hull. At low Froude number, the wave-making resistance coefficient of optimized hull is a little smaller. However, when the Froude number is higher, the coefficient of optimized hull is apparently smaller than that of parent one. That is to say the wave-making resistance performance of optimized hull has been obviously improved though the result coincides well with experimental result at low Froude number but not very well at high Froude number.

\section{CONCLUSION}

A hull lines design method, which involved wetted surface analysis and wave-making optimization, is applied with the intent of designing hulls of good resistance performance using a given set of constraints. A certain kind of quadratic curve is used to generate hull lines, of which the feasibility is proved in a brief theoretical analysis; approximate minimum wetted surface of the hull is calculated as well. Hull lines are proved smooth through mathematical procedure, in which both the first and second differentials of the line functions are derived. A program is compiled to calculate wave-making resistance of hulls using Michell integral and the Wigley hull model is taken as an example of validation. A DTMB model ship 5415 is used as an example of hull form optimization designing, applying a genetic algorithm. The particular genetic algorithm developed during this study uses the wave-making resistance as the objective function and allows automatic modification of cross section curve. Experiment result of new hull and the parent hull indicate that the hull optimization designing method is practical. With respect to the calculation result, the wave-making optimized hull is of good resistance performance.

\section{Appendix A}

Discussion of Eq. (1) for $\mathrm{x}<\mathrm{x}_{0}, \mathrm{x}=\mathrm{x}_{0}$ and $\mathrm{x}>\mathrm{x}_{0}$ is shown as follows:

1) When $\mathrm{x}<\mathrm{x}_{0}$, namely $\beta(\mathrm{x})=2 \mathrm{~S}(\mathrm{x}) / \mathrm{a}(\mathrm{x}) \mathrm{b}(\mathrm{x})<1$ :

- when $\mathrm{c}<2 / \mathrm{a}(\mathrm{x}) \mathrm{b}(\mathrm{x})$ namely $1 / \mathrm{b}(\mathrm{x})^{2}-\mathrm{a}(\mathrm{x})^{2} \mathrm{c}^{2} / 4>0$ :

$$
\begin{aligned}
S(x) & =\frac{a(x)}{2 \sqrt{1 / b(x)^{2}-a(x)^{2} c^{2} / 4}} \cdot \arcsin \sqrt{\frac{1-a(x)^{2} b(x)^{2} c^{2}}{4}} \\
& \sin \left(\beta \cdot \sqrt{1-\frac{a(x)^{2} b(x)^{2} c^{2}}{4}}\right)=\sqrt{1-\frac{a(x)^{2} b(x)^{2} c^{2}}{4}}
\end{aligned}
$$

Since there exists a unique zero solution of equation $z=\sin \beta z$, then $1 / b(x)^{2}-a(x)^{2} c^{2} / 4=0$ i.e. $c=2 / a(x) b(x)$, which contradicts the previous assumptions. Thus, Eq. (1) has no nontrivial solution.

$$
\begin{gathered}
\text { - when } \mathrm{c}=2 / \mathrm{a}(\mathrm{x}) \mathrm{b}(\mathrm{x}) \text { namely } 1 / \mathrm{b}(\mathrm{x})^{2}-\mathrm{a}(\mathrm{x})^{2} \mathrm{c}^{2} / 4=0 \text { : } \\
\mathrm{S}(\mathrm{x})=\mathrm{a}(\mathrm{x}) \mathrm{b}(\mathrm{x}) / 2
\end{gathered}
$$

then $\beta(x)=1$ and it contradicts the previous assumptions. Eq. (1) has no nontrivial solution.

- when $c>2 / a(x) b(x)$, namely $1 / b(x)^{2}-a(x)^{2} c^{2} / 4<0$ :

$$
S(x)=\frac{a(x) b(x)}{2 \sqrt{\frac{a(x)^{2} b(x)^{2} c^{2}}{4}-1}} \ln \left(\sqrt{\frac{a(x)^{2} b(x)^{2} c^{2}}{4}-1}+\frac{1}{2} a(x) b(x) c\right)
$$


then:

$$
\exp \left(\beta \sqrt{\frac{a(x)^{2} b(x)^{2} c^{2}}{4}-1}\right)=\sqrt{\frac{a(x)^{2} b(x)^{2} c^{2}}{4}-1}+\frac{1}{2} a(x) b(x) c
$$

By using Taylor expansion, an approximate solution of c can be got:

$$
\mathrm{c}(\mathrm{x})=\frac{2 \sqrt{\left(\frac{3-3 \beta(\mathrm{x})^{2}-\sqrt{-15 \beta(\mathrm{x})^{4}+24 \beta(\mathrm{x})^{3}-18 \beta(\mathrm{x})^{2}+9}}{2(\beta) \mathrm{x}^{2}}\right)^{2}}+1}{\mathrm{a}(\mathrm{x}) \mathrm{b}(\mathrm{x})}
$$

Since the equation $\mathrm{e}^{\beta z}=\mathrm{z}+\sqrt{\mathrm{z}^{2}+1}$ has nontrivial solutions when $\beta<1$, the conclusion comes out that Eq. (1) has solutions. $1_{\text {conic }}$ can be solute by considering Eq. (6) and (A6).

2) When $x=x_{0}$, namely $\beta(x)=2 S(x) / a(x) b(x)=1$ :

- when $\mathrm{c}<2 / \mathrm{a}(\mathrm{x}) \mathrm{b}(\mathrm{x})$, namely $1 / \mathrm{b}(\mathrm{x})^{2}-\mathrm{a}(\mathrm{x})^{2} \mathrm{c}^{2} / 4>0$

$$
\begin{aligned}
\mathrm{S}(\mathrm{x})= & \frac{\mathrm{a}(\mathrm{x})}{2 \sqrt{1 / \mathrm{b}(\mathrm{x})^{2}-\mathrm{a}(\mathrm{x})^{2} \mathrm{c}^{2} / 4}} \cdot \arcsin \sqrt{\frac{1-\mathrm{a}(\mathrm{x})^{2} \mathrm{~b}(\mathrm{x})^{2} \mathrm{c}^{2}}{4}} \\
& \sin \sqrt{1-\frac{\mathrm{a}(\mathrm{x})^{2} \mathrm{~b}(\mathrm{x})^{2} \mathrm{c}^{2}}{4}}=\sqrt{1-\frac{\mathrm{a}(\mathrm{x})^{2} \mathrm{~b}(\mathrm{x})^{2} \mathrm{c}^{2}}{4}}
\end{aligned}
$$

Since there exists a unique zero solution of equation $z=\sin z$, then $1 / b(x)^{2}-a(x)^{2} c^{2} / 4=0$ i.e. $c=2 / a(x) b(x)$, which contradicts the previous assumptions. Eq. (1) has no nontrivial solution.

- when $c=2 / a(x) b(x)$, namely $1 / b(x)^{2}-a(x)^{2} c^{2} / 4=0$. It is easy to verify that Eq. (1) has at least one nontrivial solution.

Substituting the equation above into Eq. (1):

$$
\begin{gathered}
\frac{\mathrm{z}^{2}}{\mathrm{~b}\left(\mathrm{x}_{0}\right)^{2}}+\frac{\mathrm{y}^{2}}{\mathrm{a}\left(\mathrm{x}_{0}\right)^{2}}+\frac{2}{\mathrm{a}\left(\mathrm{x}_{0}\right) \mathrm{b}\left(\mathrm{x}_{0}\right)} \mathrm{yz}=1 \\
\text { namely: } \\
\left(\frac{\mathrm{z}}{\mathrm{b}\left(\mathrm{x}_{0}\right)}+\frac{\mathrm{y}}{\mathrm{a}\left(\mathrm{x}_{0}\right)}\right)^{2}=1
\end{gathered}
$$

The designed curve and circular arc are both turned to lines of the same expression $\mathrm{z} / \mathrm{b}\left(\mathrm{x}_{0}\right)+\mathrm{y} / \mathrm{a}\left(\mathrm{x}_{0}\right)=1$, and the curve length

$$
1_{\text {conic }}=1_{\text {circle }}=\sqrt{\mathrm{a}^{2}+\mathrm{b}^{2}}
$$

- when $c>2 / a(x) b(x)$, namely $1 / b(x)^{2}-a(x)^{2} c^{2} / 4<0$ :

$$
\begin{aligned}
& \mathrm{S}(\mathrm{x})=\frac{\mathrm{a}(\mathrm{x}) \mathrm{b}(\mathrm{x})}{2 \sqrt{\frac{\mathrm{a}(\mathrm{x})^{2} \mathrm{~b}(\mathrm{x})^{2} \mathrm{c}^{2}}{4}-1}} \cdot \ln \left(\sqrt{\frac{\mathrm{a}(\mathrm{x})^{2} \mathrm{~b}(\mathrm{x})^{2} \mathrm{c}^{2}}{4}-1}+\frac{1}{2} \mathrm{a}(\mathrm{x}) \mathrm{b}(\mathrm{x}) \mathrm{c}\right) \\
& \text { then: } \\
& \exp \left(\beta \sqrt{\frac{a(x)^{2} b(x)^{2} c^{2}}{4}-1}\right)=\sqrt{\frac{a(x)^{2} b(x)^{2} c^{2}}{4}}-1+\frac{1}{2} a(x) b(x) c
\end{aligned}
$$

Since there exists a unique zero solution of equation $e^{z}=z+\sqrt{z^{2}+1}$, then $1 / b(x)^{2}-a(x)^{2} c^{2} / 4=0$ i.e. $c=2 / a(x) b(x)$, which contradicts the previous assumptions. Thus, Eq. (1) has no nontrivial solution.

3) When $x_{0}<x$, namely $\beta(x)=2 S(x) / a(x) b(x)>1$

- when $\mathrm{c}<2 / \mathrm{a}(\mathrm{x}) \mathrm{b}(\mathrm{x})$, namely $1 / \mathrm{b}(\mathrm{x})^{2}-\mathrm{a}(\mathrm{x})^{2} \mathrm{c}^{2} / 4>0$ :

$$
\begin{aligned}
S(x) & =\frac{a(x)}{2 \sqrt{\frac{1 / b(x)^{2}-a(x)^{2} c^{2}}{4}}} \cdot \arcsin \sqrt{\frac{1-a(x)^{2} b(x)^{2} c^{2}}{4}} \\
& \sin \left(\beta \cdot \sqrt{1-\frac{a(x)^{2} b(x)^{2} c^{2}}{4}}\right)=\sqrt{1-\frac{a(x)^{2} b(x)^{2} c^{2}}{4}}
\end{aligned}
$$

By using Taylor expansion, an approximate solution of c can be got: 


$$
\mathrm{c}(\mathrm{x})=\frac{2 \sqrt{1-\frac{10 \beta(\mathrm{x})-\sqrt{120 \beta(\mathrm{x})-20 \beta(\mathrm{x})^{2}}}{\beta(\mathrm{x})^{3}}}}{\mathrm{a}(\mathrm{x}) \mathrm{b}(\mathrm{x})}
$$

Since the equation $\mathrm{z}=\operatorname{sinz}$ has nontrivial solutions when $\beta>1$, Eq. (1) has at least a nontrivial solution. Curve length $1_{\text {conic }}$ can be calculated by solving Eq. (6) and (A15).

- when $c=2 / a(x) b(x)$, namely $1 / b(x)^{2}-a(x)^{2} c^{2} / 4=0$ :

$$
\mathrm{S}(\mathrm{x})=\mathrm{a}(\mathrm{x}) \mathrm{b}(\mathrm{x}) / 2
$$

That is $\beta(x)=1$, which contradicts the previous assumption $\beta(x)>1$. Thus, Eq. (1) has no nontrivial solution.

- when $\mathrm{c}>2 / \mathrm{a}(\mathrm{x}) \mathrm{b}(\mathrm{x})$, namely $1 / \mathrm{b}(\mathrm{x})^{2}-\mathrm{a}(\mathrm{x})^{2} \mathrm{c}^{2} / 4<0$ :

$$
\begin{aligned}
& S(x)=\frac{a(x) b(x)}{2 \sqrt{\frac{a(x)^{2} b(x)^{2} c^{2}}{4}}-1} \ln \left(\sqrt{\frac{a(x)^{2} b(x)^{2} c^{2}}{4}-1}+\frac{1}{2} a(x) b(x) c\right) \\
& \exp \left(\beta \sqrt{\frac{a(x)^{2} b(x)^{2} c^{2}}{4}}-1\right)=\sqrt{\frac{a(x)^{2} b(x)^{2} c^{2}}{4}}-1+\frac{1}{2} a(x) b(x) c
\end{aligned}
$$

Since the equation $e^{\beta z}=z+\sqrt{z^{2}+1}$ has no solutions when $\beta>1$, Eq. (1) has no solutions yet.

\section{Appendix B}

Discussion of the continuity of waterlines function is shown as follows:

The first derivative of $\mathrm{c}$ with respect to $\mathrm{z}$ is calculated as follows:

1) When $x \in\left[0, x_{0}\right), c=c(x)$ is defined by Eq. (8). Let:

$$
\mathrm{O}(\mathrm{x})=\sqrt{\frac{1}{4} \mathrm{a}(\mathrm{x})^{2} \mathrm{~b}(\mathrm{x})^{2} \mathrm{c}(\mathrm{x})^{2}-1}
$$

Eq. (8) can be written as:

$$
\beta(x) O(x)=\ln \left(O(x)+\sqrt{O(x)^{2}+1}\right)
$$

Differentiate both sides of the equation with respect to $x$, and then we have:

$$
\mathrm{O}(\mathrm{x}) \mathrm{O}^{\prime}(\mathrm{x})=\frac{\beta^{\prime}(\mathrm{x}) \mathrm{O}(\mathrm{x})^{2} \sqrt{\mathrm{O}(\mathrm{x})^{2}+1}}{1-\beta(\mathrm{x}) \sqrt{\mathrm{O}(\mathrm{x})^{2}+1}}
$$

Let $\lim _{x \rightarrow x_{0}^{+}} O(x) O^{\prime}(x)=$ I. A simple form of Eq. (B2) can be got by using L'Hôpital's Rule:

$$
\begin{gathered}
I=\lim _{x \rightarrow x_{0}^{+}} O(x) O^{\prime}(x)=\beta^{\prime}\left(x_{0}\right) \frac{2 I}{-\beta^{\prime}\left(x_{0}\right)-I} \\
\text { namely: } \\
\lim _{x \rightarrow x_{0}^{+}} O(x) O^{\prime}(x)=I=-3 \beta^{\prime}\left(x_{0}\right) \\
\text { then: } \\
O^{\prime}(x)=-\frac{a^{\prime}(x) a(x) b(x)^{2} c(x)^{2}+a(x)^{2} b(x) b^{\prime}(x) c(x)^{2}+a(x)^{2} b(x)^{2} c(x) c^{\prime}(x)}{4 \sqrt{1-\frac{1}{4} a(x)^{2} b(x)^{2} c(x)^{2}}}
\end{gathered}
$$

Solve Eq. (B1) and (B5), then:

$$
c^{\prime}(x)=\frac{4 O(x) O^{\prime}(x)-a^{\prime}(x) a(x) b(x)^{2} c(x)^{2}-a(x)^{2} b(x) b^{\prime}(x) c(x)^{2}}{a(x)^{2} b(x)^{2} c(x)}
$$

Simplify the equation, and we can get the left-hand limit of $c^{\prime}\left(x^{\prime}\right)$ at $x_{0}$ :

$$
\lim _{x \rightarrow x_{0}^{+}} c^{\prime}(x)=-\frac{6 \beta^{\prime}\left(x_{0}\right)+a^{\prime}\left(x_{0}\right) b\left(x_{0}\right) c\left(x_{0}\right)+a\left(x_{0}\right) b^{\prime}\left(x_{0}\right) c\left(x_{0}\right)}{a\left(x_{0}\right) b\left(x_{0}\right)}
$$

2) When $x \in\left(x_{0}, L / 2\right], c=c(x)$ is defined by Eq. (9). Let:

$$
\mathrm{O}(\mathrm{x})=4 \sqrt{1-\frac{1}{4} \mathrm{a}(\mathrm{x})^{2} \mathrm{~b}(\mathrm{x})^{2} \mathrm{c}(\mathrm{x})^{2}}
$$


Eq. (9) can be written as:

$$
\sin (\beta(x) O(x))=O(x)
$$

Differentiate both sides of the equation with respect to $\mathrm{z}$, and then we have:

$$
\mathrm{O}(\mathrm{x}) \mathrm{O}^{\prime}(\mathrm{x})=\frac{\beta^{\prime}(\mathrm{x}) \mathrm{O}(\mathrm{x})^{2} \cos (\beta(\mathrm{x}) \mathrm{O}(\mathrm{x}))}{1-\beta(\mathrm{x}) \cos (\beta(\mathrm{x}) \mathrm{O}(\mathrm{x}))}
$$

Let $\lim _{\mathrm{x} \rightarrow \mathrm{x}_{0}^{+}} \mathrm{O}(\mathrm{x}) \mathrm{O}^{\prime}(\mathrm{x})=\mathrm{I}$. A simple form of Eq. (B9) can be got by using L'Hôpital's Rule:

$$
\begin{gathered}
I=\lim _{x \rightarrow x_{0}^{+}} O(x) O^{\prime}(x)=\beta^{\prime}\left(x_{0}\right) \frac{2 I}{I-\beta^{\prime}\left(x_{0}\right)} \\
\text { namely: } \\
\lim _{x \rightarrow x_{0}^{+}} O(x) O^{\prime}(x)=I=3 \beta^{\prime}\left(x_{0}\right) \\
O^{\prime}(x)=-\frac{a^{\prime}(x) a(x) b(x)^{2} c(x)^{2}+a(x)^{2} b(x) b^{\prime}(x) c(x)^{2}+a(x)^{2} b(x)^{2} c(x) c^{\prime}(x)}{4 \sqrt{1-\frac{1}{4} a(x)^{2} b(x)^{2} c(x)^{2}}}
\end{gathered}
$$

Solve Eq. (B8) and (B13):

$$
c^{\prime}(x)=-\frac{4 O(x) O^{\prime}(x)+a^{\prime}(x) a(x) b(x)^{2} c(x)^{2}+a(x)^{2} b(x) b^{\prime}(x) c(x)^{2}}{a(x)^{2} b(x)^{2} c(x)}
$$

Simplify the equation, and we can get the right-hand limit of $\mathrm{c}^{\prime}\left(\mathrm{x}^{\mathrm{a}}\right)$ at $\mathrm{x}_{0}$ :

$$
\lim _{x \rightarrow x_{0}^{+}} c^{\prime}(x)=-\frac{6 \beta^{\prime}\left(x_{0}\right)+a^{\prime}\left(x_{0}\right) b\left(x_{0}\right) c\left(x_{0}\right)+a\left(x_{0}\right) b^{\prime}\left(x_{0}\right) c\left(x_{0}\right)}{a\left(x_{0}\right) b\left(x_{0}\right)}
$$

From Eq. (B7) and (B14), we have $\lim _{x \rightarrow x_{0}^{-}} c^{\prime}(x)=\lim _{x \rightarrow x_{0}^{+}} c^{\prime}(x)$, namely the left-hand and right-hand limits are equal as $x \rightarrow x_{0}$, that is to say $c^{\prime}(\mathrm{x})$ is continuous in domain $\left[\mathrm{x}_{0}, \mathrm{~L} / 2\right]$.

When $\mathrm{z}=\mathrm{h}$, the waterline defined by Eq. (1) can be expressed as:

$$
y(x)=\frac{-a(x)^{2} c(x) h}{2}+a(x) \sqrt{1-\left(\frac{1}{b(x)^{2}}-\frac{a(x)^{2} c(x)^{2}}{4}\right) h^{2}}, x \in[0, L / 2]
$$

Since $a(x), b(x), c(x)$ and their first derivatives are all continuous, and it is not difficult to prove that the second derivatives of $a(x), b(x), c(x)$ is continuous, the first and second derivative of $y$ can be written as:

$$
\begin{gathered}
y^{\prime}(x)=-a^{\prime} a h-\frac{1}{2} a^{2} c^{\prime} h+a^{\prime} \sqrt{1-\left(\frac{1}{b^{2}}-\frac{1}{4} a^{2} c^{2}\right) h^{2}}+\frac{a h^{2}\left(\frac{b^{\prime}}{b^{3}}+\frac{1}{4} a a^{\prime} c^{2}+\frac{1}{4} a^{2} c c^{\prime}\right)}{\sqrt{1-\left(\frac{1}{b^{2}}-\frac{1}{4} a^{2} c^{2}\right) h^{2}}}, x \in[0, L / 2] \\
y^{\prime \prime}(x)=-a^{\prime 2} c z-2 a a^{\prime} c^{\prime} z-a c a " z-\frac{1}{2} a^{2} c^{\prime \prime} z+a^{\prime \prime} \sqrt{1-\left(\frac{1}{b^{2}}-\frac{1}{4} a^{2} c^{2}\right) z^{2}} \\
-\frac{a^{\prime}\left(-\frac{2 b^{\prime}}{b^{3}}-\frac{1}{2} a c^{2} a^{\prime}-\frac{1}{2} a^{2} c c^{\prime}\right) z^{2}}{\sqrt{1-\left(\frac{1}{b^{2}}-\frac{1}{4} a^{2} c^{2}\right) z^{2}}}-\frac{1}{4} \frac{a\left(-\frac{2 b^{\prime}}{b^{3}}-\frac{1}{2} a c^{2} a^{\prime}-\frac{1}{2} a^{2} c c^{\prime}\right)^{2} z^{4}}{\left(1-\left(\frac{1}{b^{2}}-\frac{1}{4} a^{2} c^{2}\right) z^{2}\right)^{3 / 2}}+ \\
-\frac{1}{2} \frac{1}{\sqrt{1-\left(\frac{1}{b^{2}}-\frac{1}{4} a^{2} c^{2}\right) z^{2}}}\left[a\left(\frac{6 b^{\prime 2}}{b^{4}}-\frac{2 b^{\prime \prime}}{b^{3}}-\frac{1}{2} a^{\prime^{2} c^{2}}-2 a c a^{\prime} c^{\prime}-\frac{1}{2} a c^{2} a^{\prime \prime}-\frac{1}{2} a^{2} c^{\prime 2}-\frac{1}{2} a^{2} c c^{\prime \prime}\right) z^{2}\right], x \in[0, L / 2]
\end{gathered}
$$

Both Eq. (B16) and (B17) are smooth and continuous.

\section{BIBLIOGRAPHY}

1. Abramowski T., Żelazny K. and Szelangiewicz T.: Numerical Analysis of Influence of Ship Hull Form Modification On Ship Resistance and Propulsion Characteristics, Polish Maritime Research, 17(1): 10-13, 2010.
2. Chen P. and Huang C.: An Inverse Hull Design Problem in Optimizing the Desired Wake of Ship, Journal of Ship Research, 46(2): 138-147, 2002.

3. Chen P., Huang C. and Fang M.: An Inverse Design Approach in Determining the Optimal Shape of Bulbous Bow with Experimental Verification, Journal of Ship Research, 50(1): 1-14, 2006. 
4. Doctors L. J., Day A. H. and Clelland D.: Resistance of a Ship Undergoing Oscillatory Motion, Journal of Ship Research, 54(13): 120-12, 2010.

5. Gammon M. A.: Optimization of Fishing Vessels Using a MultiObjective Genetic Algorithm, Ocean Engineering, 38(10): 10541064, 2011.

6. Ghassemi H. and Ghiasi M. A.: Combined Method for the Hydrodynamic Characteristics of Planing Crafts, Ocean Engineering, 35(3-4): 310-322, 2008.

7. Grigoropoulos G. J. and Chalkias D. S.: Hull-Form Optimization in Calm and Rough Water, Computer-Aided Design, 42(11): 977-984, 2010.

8. Havelock T. H.: Wave Resistance Theory and its Application to Ship Problems, Society of Naval Architects and Marine Engineers, 1951.

9. Kim H. and Yang C.: A New Surface Modification Approach for Cfd-Based Hull Form Optimization, Journal of Hydrodynamics, Ser. B, 22 (5, Supplement 1): 520-525, 2010.

10.Li X.: Multiobjective Optimization and Multiattribute Decision Making Study of Ship's Principal Parameters in Conceptual Design, Journal of Ship Research, 53(2): 83-92, 2009.

11.Lu C., Lin Y. and Ji Z.: Free Trim Calculation Using Genetic Algorithm Based On Nurbs Shipform, International Shipbuilding Progress, 54(1): 45-62, 2007.

12.Lu C., Lin Y., Ji Z. and Chen M.: Ship Hull Representation with a Single Nurbs Surface, Proceedings of the International Offshore and Polar Engineering Conference, Seoul, Korea, 2005.

13.Michell J. H.: The Wave Resistance of a Ship, Philosophy Magazine, 5(45): 106-123, 1898.

14.Pérez F. L., Clemente J. A., Suárez J. A. and González J. M.: Parametric Generation, Modeling, and Fairing of Simple Hull Lines with the Use of Nonuniform Rational B-Spline Surfaces, Journal of Ship Research, 52(1): 1-15, 2008.

15.Peri D. and Campana E. F.: Multidisciplinary Design Optimization of a Naval Surface Combatant, Journal of Ship Research, 47(1): 1-12, 2003.

16.Peri D., Rossetti M. and Campana E. F.: Design Optimization of Ship Hulls Via Cfd Techniques, Journal of Ship Research, 45(2): 140-149, 2001.
17.Sarioz E.: An Optimization Approach for Fairing of Ship Hull Forms, Ocean Engineering, 33(16): 2105-2118, 2006.

18.TUCK E. O.: The Wave Resistance Formula of J.H. Michell (1898) and its Significance to Recent Research in Ship Hydrodynamics, The Journal of the Australian Mathematical Society. Series B. Applied Mathematics, 30(4): 365-377, 1989.

19.Tzabiras G. D.: A Method for Predicting the Influence of an Additive Bulb On Ship Resistance, 8th International conference on hydrodynamics, Athens, Greece, 2008.

20.Wilson W., Hendrix D. and Gorski J.: Hull Form Optimization for Early Stage Ship Design, Naval Engineers Journal, 122(2): 53-65, 2010.

21.Yoo J.: Design of Ship's Bow Form by Potential-Based Panel Method, Ocean Engineering, 34(8-9): 1089-1095, 2007.

22.Zhang B., Ma K. and Ji Z.: The Optimization of the Hull Form with the Minimum Wave Making Resistance Based On Rankine Source Method, Journal of Hydrodynamics, 21(2): 277-284, 2009.

23.Zhang P., Zhu D. and Leng W.: Parametric Approach to Design of Hull Forms, Journal of Hydrodynamics, Ser. B, 20(6): 804$810,2008$.

\section{CONTACT WITH THE AUTHORS}

Jianglong Suna), Ph.D., Assoc. Prof. Xujian Lva), 1), Ph.D.

Weibin Liua), Ph.D., Assoc. Prof. Hanwen Ningb), Ph.D.

Xianwen Chen ${ }^{\text {a) }}$, Master Graduate Student

a) Department of Naval Architecture \& Ocean Engineering,

Huazhong University of Science \& Technology, Wuhan 430074, P.R. China

b) School of Statistics and Mathematics, Zhongnan University of Economics and Law, Wuhan 430074, P.R. China

1) Corresponding author. e-mail: lv.xujian@gmail.com 